\title{
КОНСТРУКТИВИЗМ ОТНОШЕНИЙ СОБСТВЕННОСТИ В СЕТЕВОЙ СИСТЕМЕ КООРДИНАЦИИ СВЯЗЕЙ
}

\author{
(c) 2019 Мокичев Сергей Дмитриевич \\ кандидат экономических наук, доцент \\ Казанский (Приволжский) федеральный университет, Россия, Казань \\ E-mail: mokichev.kpfu@mail.ru \\ (c) 2019 Зульфакарова Лилия Фаридовна \\ кандидат экономических наук, доцент \\ Казанский (Приволжский) федеральный университет, Россия, Казань \\ E-mail: zulfakarova@mail.ru \\ (c) 2019 Вахитова Тина Муратовна \\ кандидат экономических наук, доцент \\ Казанский (Приволжский) федеральный университет, Россия, Казань \\ E-mail: tvahitova@yandex.ru
}

В статье рассматривается подход со стороны теории конструктивизма, которая описывает структурные характеристики отношений собственности, принимая за основу сетевую систему координации связей. Формирование сетевого построения и нового, неиерархического пути координирования связей, отражает новые экономические реалии, связанные с сильной взаимозависимостью субъектов собственности. Формирование экономики знаний, развитие глобализации, интеграция субъектов собственности привели к ускорению развития инноваций, к новому качеству отношений собственности. За инновациями кроется масштабная агломерация, состоящая из социального, инновационного, интеллектуального, финансового совокупности капиталов, что формирует появление “инноваций в инновациях” и обуславливает актуальность изучения сетевой системы координации связей.

Ключевые слова: Собственность, отношения собственности, сетевая структура, тройная спираль, отношения собственности, экономика, инновационная система, инновации, поведенческая экономика, экономическая теория.

Главной особенностью сетевой системы является сетевая логика использования собственности, придающая отношениям присвоения особые качества и функции. Это показывает на динамичное обновление ситуации в области отношений собственности взаимодействующее с определённой институциональной средой, где горизонтальные сетевые связи являются неотъемлемой частью процесса кооперации собственников в процессе производства. Здесь наиболее рельефно проявляется конструктивизм отношений собственности, нацеленный на разработку и создание инноваций. Динамика “инноваций в инновациях” является движущей силой для формирования конструктивизма отношений собственности в сетевой системе координации связей. Теория конструктивизма отношений собственности позволяет не только проверить на прочность механизмы взаимоотношений субъектов собственности, но и скоординировать их действия. Также данная теория будет полезна в плане развития партнерства, которое привело бы к смешанной социально-экономической структуре с положительными качествами сплоченности спиральных структур субъектов и повышенной приспособляемости к переменам и модификациям внешней среды. Происходит трансформация в поведении всех экономических агентов. Использование модели тройной спирали инсценирует институциональные процессы, ведущие к определению новых "правил игры” в сетевом пространстве, выявляет основной генерирующий источник экономического и социального развития, что позволяет вывести взаимодействие участников инновационного процесса на новый уровень. В двухтысячные годы, конструкция партнерства субъектов собственности начала проникать в экономическую 
практику в качестве платформы формирования сетевых структур и генерации инноваций [3], как конструкция для конфигурации современных отношений собственности. Нередко она начала проникать и на научные конференции, в форме нового метода становления процессов объединений различных субъектов собственности и формированию целостного рынка знаний.

Мы отразили конструктивизм отношений собственности в анализе тройной спирали, при анализе региональных институциональных образований и при обосновании теории эволюции отношений собственности в системе координации связей [1], что позволило предложить новый механизм конструкции отношений собственности, который может обеспечить самостоятельный рост сложных многовариантных сетевых систем. Конструктивизм отношений собственности, созданный в динамичной инновационной среде, гармонизируется на всех уровнях.

Развитие теории конструктивизма отношений собственности объясняется переходом экономических систем к сетевому строению. Этот цивилизационный сдвиг вызван высокой степенью неопределенности и повышенной степенью зависимости субъектов друг от друга. Преобразование отношений собственности в современную, чрезвычайно пластичную конструкцию, а также переход к новому способу организации взаимодействия между субъектами обусловлено постоянными динамическими изменениями, которые они часто воспринимают как «тиранию момента». Инновационная экономика вынуждает субъектов собственности быть гибкими, приспосабливаться к изменяющемуся миру и адекватно действовать для того, чтобы выжить. Для активизации инновационной деятельности необходимо такая конструкция отношений собственности, которая отличается высокой адаптивностью к установлению координационных связей со всеми участниками инновационной сферы. В этой связи необходим переход экономических систем к сетевому строению, в котором координация связей будет наиболее эффективной. Сегодня уже очевидно, что прогнозировать, конструировать отношения собственности нельзя исключительно с позиции рационального знания индустриальной системы. Здесь нужны внерациональные когнитивные механизмы, которые позволяют расширить критерии научности отношений собственности и выйти за пределы их канонического толкования.
Сетевой способ координации связей субъектов собственности меняет привычное построение отношений присвоения на сетевое, которое будет много пластичнее нежели модель иерархии.

Практика рыночных контрактов субъектов собственности переходит в онлайн состояние, которое не базируется на ценовых сигнатурах, но функционирует при помощи непосредственной кооперации собственников, а также кооперации между производителями и потребителями. Крупные собственники, в процессе создания более совершенной экономической среды, параллельно развивают координирующие платформы, где образовываются экономические сети [10]. Меняется уровень инновационной активности субъектов собственности, усиливается координация связей между собственниками в сферах науки, образования, производства, в том числе на уровнях системы воспроизводства научных кадров, организационного обеспечения цепи “прикладные исследования - опытно-конструкторские разработки - производство”. Горизонтальные связи, в свою очередь, служат плацдармом для образования особых отношений собственности, которые бы опирались на принцип сотрудничества, таким образом удаляясь от любых иерархических структур с замкнутым циклом и вертикальным подчинением. В данном контексте, сотрудничество или «коллаборация» существует как механизм взаимосвязи владельцев, при котором субъекты сотрудничества непрерывно совершают обмен знаниями, усиливают и реализуют совокупный потенциал, а также происходит направленный менеджмент решений.

В научных экономических источниках данный механизм получил названия "координации связи без иерархии” [6], или “коллаборативное управление" - "Colloborative Governance” [2].

Процесс участия владельцев в сети сопровождается обменом ресурсами, идеями, согласованием планов действий. по созданию инновационного продукта. Отношения собственности становятся плавным системообразующим элементом системы сетевой экономики. Активное сотрудничество субъектов собственности раскрывается через их активность в обеспечении максимально полной, многогранной и эффективной реализации возможностей сетевой экономики для достижения оптимального удовлетворения их интересов. Этот подход актуа- 
лизируется в рамках эволюционной теории активности отношений собственности и приводит к созданию преимуществ сетевого взаимодействия субъектов собственности:

- высокая скорость приспосабливания к динамике внешней среды;

- ликвидация дублирующихся функций;

- ликвидация, либо сведение к минимуму территориальных ограничений;

- повышенная степень инновационной активности;

- сосредоточение внимания субъектов собственности на модернизирование ключевых компетенций;

- мобилизация в сеть компетентных партнеров, обладающих необходимым ресурсным потенциалом;

- возможность выстраивания консолидации субъектов для реализации трудоёмких и ресурсоёмких задач с большим числом участников.

В виду того, что сетевая экономика базируется на принципе сотрудничества и инноваций, который меняет деятельность субъектов собственности, для них характерен сознательный интерес владельцев к кооперативным связям, условию конвергенции компетенций и взаимозаменяемости ресурсов на базе выявления сильных и слабых сторон субъектов собственности в сетевой экономике, селекции субъектов собственности по установленным критериям; к установлению оценки эффективности сотрудничества собственников, формализации компетенций, осуществлению анализа и оценки ресурсного потенциала, созданию внутренней и внешней культуры взаимодействия собственников на основе коллаборации, конструированию интеграционного устройства учитывая единство целей и стратегических путей эволюции и роста [7].

На базе координации связей в сетевом взаимодействии субъектов собственности возникает новая модель конструкции отношений собственности, трансформирующая традиционные представления о сущности отношений присвоения. Сетевая координация отношений между субъектами собственности - достаточно стабильная структура, основанная на сочетании их потребностей и целей, комплексе внутренних принципов и регламентов, культуре внутри и снаружи сети, а также на принципе уникальных отношений собственности. Демонстрируя определенный тип заинтересованности и инициа- тивы к инновационной деятельности, субъект собственности развивает области координации отношений, непосредственно связанных с инновациями, которые в виду своей уникальности могут разрабатывать новые знания, технологии и методы производства. Собственники генерируют и привлекают набор инструментов координации связей с целью организации общей среды кооперации.

Координация связей между субъектами собственности может иметь в качестве своего объекта практически любую область деятельности собственников:

- научно-техническую деятельность;

- инновационную деятельность;

- формирование и развитие отношений, знаний, способностей, связанных с разработкой и производством высокотехнологичной продукции, обладающий уникальными потребительскими свойствами;

- эффективное использование интеллектуального потенциала;

- систему управления интеллектуальной собственностью.

Конструктивизм отношений собственности в процессе формирования координационных связей между субъектами опирается на два исходных критерия: 1) основные формы, которые могут принимать координационные соглашения; 2) различные собственники, участвующие в координации.

Можно выделить четыре координационные формы обмена информацией между собственниками:

1. создание совместных подразделений НИОКР;

2. специализацию;

3. совместное использование лицензий;

4. создание совместного предприятия.

При анализе различных собственников, участвующих в координации, выделяются виды компетенций собственника, способные оказать необходимый полезный эффект сетевой организации. В случае направленности данных компетенций по пути компенсации слабых сторон субъекта, то их можно назвать компенсаторами, если на усиление компетенций - усилителями. По мере развития координационных связей происходит ранжирование компетенций по их способности максимизировать компенсирующий или усиливающий эффекты.

Идентифицировать потенциальные возмож- 
ности собственника с двойным эффектом намного сложнее. Обеспечение собственниками сбалансированной, органичной и одновременной работы компенсаторов и усилителей компетенций, имеет принципиальное значение для успешного инновационного процесса.

Затраты на анализ случайных возможностей могут быть сведены к минимуму благодаря проработанной координации связей партнёров по собственности. Данные связи на своём качественном уровне и с высокой степенью проработки содержат количественный анализ степени соответствия этих потенциальных возможностей для создания инновационного продукта. Происходит их ранжирование по степени возможности, что позволяет определить риск и сделать оценку. Как отмечает Дэвид Тиис [11], направленность на генерацию ценностей и осознание потенциала отношений могут привести к кардинальным трансформациям в отношениях собственности.

Одна из главных выгод наличия координации связей в сети между собственниками состоит в предупреждении фатальных решений, которые принимаются в цейтноте используя случайные методы оценки альтернатив и потенциалов субъектов присвоения. Решением проблемы является “колесо возможностей” - метод поэтапного создания стратегии по производству инновационного продукта, который воспроизводится путём ответа на такие фундаментальные вопросы как:

- В чём состоят сильные и слабые стороны субъектов собственности вошедших в сетевую структуру для создания инновационного продукта?

- Как выглядят приоритеты собственников в плане укрепления сильных сторон и устранения слабых?

- Какие альтернативные возможности для партнерства субъектов собственности мы имеем?

- Соответствуют ли потенциальные возможности субъектов параметрам сетевой организации в инновационной экономике?

Процедура построения "колеса возможностей” организуется и запускается с принятия решения о горизонтальной координации связей в сетевом образовании. Начинаются изменения институциональной активности законодателей, обладателей прав и носителей обязанностей [9], уменьшается неопределенность и реагировании на сложные ситуации через разделение рисков [5], наступает процесс перераспределения прав собственности [4].

Необходима новая структура мотивы для максимально возможного уменьшения периода между изобретением и внедрением инновации. Собственники-партнеры разрабатывают согласованный план развития инновационного процесса, в котором предусматривают перенос потенциальных возможностей каждого в “колесо возможностей”. Затем вырабатывают критерии отбора будущих альтернатив на основе анализа сильных и слабых сторон субъектов собственности для соответствия их инновационной экономике. После этапа по сопоставлению альтернативных путей концентрации собственности при помощи «колеса возможностей» устанавливая при этом критерий инновационности, становится возможным определить важнейшие и основные направления инновационной деятельности. Это очень сенситивная сфера отношений собственности - иногда партнеры по координации связей в сетевой структуре тратят годы на разработку своих компетенций для инновационной экономики и могут негативно отреагировать в случае отторжения предлагаемых ими возможностей не подвергнув их необходимому анализу и процессуальному обращению по определению соответствия инновационной экономике. Бизнес-взаимоотношения собственников можно определить в виде непрерывного процесса, в котором формируются сильные социальные, экономические, технические взаимосвязи с целью снижения издержек и повышения ценности, достигая тем самым взаимовыгодного решения проблем [3]. Как отмечает А. Митчелл [8]: “В реальной жизни обмен между людьми гораздо богаче, нежели рыночная сделка. В процессе общения происходит обмен и совместное пользование не только материальными, но и моральными ценностями...”

Конструктивизм отношений собственности в сетевом образовании порождает когерентный, взаимосвязанный и взаимосогласованный мир. Конструирующий собственник и конструируемые им отношения присвоения составляют процессуальное единство. Конструирование означает, что собственник берет на себя весь груз ответственности за реализацию отношений собственности в сфере инновационного производства. Принцип ответственности ставится во главу угла. Собственник конструирует 
отношения присвоения с позиции инновационной экономики и синергетического эффекта. Конструктивизм определяет роль собственника, установок его сознания и его ценностных предпочтений в выборе возможных путей развития инновационной экономики в состоянии неустойчивости национальной инновационной системы. В процессе деятельности и воспроизводства собственник постоянно сталкивается с кардинально новыми обстоятельствами, ранее не встречавшимися. Находясь в сети, собственник обретает способность к пониманию оптимального способа достижения конкретной цели и возможность использования горизонтальной координации связей для селекции средств по её достижению. В данной ситуации происходит отказ от возможности реализации альтернативных целей ценность которых ниже, но достижение которых, как считает собственник, сопровождалось бы меньшим риском для частной собственности. Тем самым получается, что упускаемая ценность - есть его издержки со стороны субъективной оценки. Чаще всего собственники выбирают способ функционирования в сетевом образовании ввиду повышенной субъективной оценки инновационной цели по сравнению с издержками, которые могут присутствовать в процессе погони за более высоким доходом от собственности.

\section{Библиографический список}

1. Мокичев С.В., Мокичев С.Д. Развитие инновационной кооперации как условие трансформации структуры собственности / Журнал экономической теории. 2012. № 3. с.27-38.

2. Andersson T, Schwaag-Serger S, Sörvik J, Wise E. Cluster Policies Whitebook. IKED - International Organization for Knowledge Economy and Enterprise Development, 2004. P. 266.

3. Anderson, J \& Narus J (1998) Business Marketing: Understand What Customers Value / Harvard Business Review, Nov/Dec98, Vol. 76 Issue 6, p53-65.

4. Demsetz H. Toward a Theory of Property Rights / The American Economic Review, Vol. 57, No.2, Papers and Proceedings of the Seventy-ninth Annual Meeting of the American Economic Association. (May, 1967), pp. 347359.

5. Gibbons R., Farrell J. Cheap Talk about Specific Investments / The Journal of Law, Economics, and Organization, Volume 11, Issue 2, October 1995, Pages 313-334.

6. Hasumi Y. Roles of International Organizations and the EU in Governing the Global Economy: Implications for Regional Cooperation in Asia / The Third EU-NESCA Workshop, Korea University, May 2007.

7. Mokichev S.D., Mokichev, S.V., Gerasimova V. Nano-economics In a National System of Innovation / Procedia Economics and Finance, 2013. p. 288-297.

8. Mitchell A. It's Now a Matter of Trust / Marketing Business, No33, April, 2001.

9. Riker W. H., Itai Sened. A Political Theory of the Origin of Property Rights / American Journal of Political Science, Vol. 35, No. 4, 1991.p.951-969

10. Tapscott D., Anthony D. Williams, Wikinomics: How Mass Collaboration Changes Everything / New York: Penguin, 2007, 320 pp.

11. Teece David J. Managing Intellectual Capital: Organizational, Strategic, and Policy Dimensions / Oxford University Press, 2002. ISBN-13: 9780198295426. 